\title{
Protective effect of calcium nanophosphate and CPP-ACP agents on enamel erosion
}

\begin{abstract}
Fabíola Galbiatti de Carvalho(a) Veruska Lima Moura Brasil(b) Tiago João da Silva Filho(b) Hugo Lemes Carlo(b) Rogério Lacerda dos Santos ${ }^{(a)}$ Bruno Alessandro Silva Guedes de Lima ${ }^{(c)}$
\end{abstract}

(a) Department of Biological Science, Division of Dentistry, Universidade Federal de Campina Grande - UFCG, Patos, PB, Brazil.

(b) Department of Operative Dentistry, Centro de Ciências da Saúde, Universidade Federal da Paraíba - UFPB, João Pessoa, PB, Brazil.

(c) Department of Mechanical Technology, Laboratório de Solidificação Rápida, Universidade Federal da Paraíba - UFPB, João Pessoa, PB, Brazil.

Declaration of Interests: The authors certify that they have no commercial or associative interest that represents a conflict of interest in connection with the manuscript.

Corresponding Author:

Fabíola Galbiatti de Carvalho

Email: fabigalbi@yahoo.com.br

htrp://dx.doi.org/10.1590/S1806-83242013000600004

Submitted: Feb 20, 2013

Accepted for publication: Aug 12, 2013

Last revision: Aug 26, 2013
Abstract: The aim of this study was to assess the effect of different remineralizing agents on enamel microhardness (KHN) and surface topography after an erosive challenge. Forty-eight human enamel specimens $(4 \times 4 \mathrm{~mm})$ were randomly assigned to 4 groups: control (no treatment), fluoride varnish, calcium nanophosphate paste and casein phosphopeptide-amorphous calcium phosphate paste (CPP-ACP). Both pastes were applied for 5 minutes, and fluoride varnish, for 24 h. Four daily erosive cycles of 5 minutes of immersion in a cola drink and $2 \mathrm{~h}$ in artificial saliva were conducted for 5 days. KHN readings were performed at baseline and after 5 days. The percentage of enamel hardness change $(\% \mathrm{KHN})$ was obtained after erosion. The surface topography was evaluated by atomic force microscopy (AFM). The data were tested using ANOVA, Tukey's and paired-T tests $(p<0.05)$. After an erosive challenge, there was no statistically significant difference between the control $(96.8 \pm 11.4 \mathrm{KHN} / 72.4 \pm 3.0 \% \mathrm{KHN})$ and the varnish $(91.7 \pm 14.1 \mathrm{KHN} / 73.4 \pm 5.5 \% \mathrm{KHN})$ groups. The nanophosphate group showed lower enamel hardness loss (187.2 \pm 27.9 / $49.0 \pm 7.9 \% \mathrm{KHN})$, compared with the CPP-ACP group (141.8 $\pm 16.5 /$ $60.6 \pm 4.0 \% \mathrm{KHN})$, and both were statistically different from the varnish and the control groups. AFM images showed a rough surface for the control and the varnish groups, a non-homogeneous layer with globular irregularities for CPP-ACP, and a thick homogeneous layer for the nanophosphate group. None of the agents provided protection against the development of erosion; however, nanophosphate paste was able to reduce enamel surface softening after the erosive challenge.

Descriptors: Tooth Erosion; Fluorides; Microscopy, Atomic Force.

\section{Introduction}

Dental erosion is defined as the loss of tooth substance due to chemical processes not involving bacteria. ${ }^{1}$ Although erosive lesions have a multifactorial etiology, the increasing consumption of acidic food and soft drinks has become an important factor driving their development. ${ }^{2-4}$

Many strategies have been developed for the prevention and treatment of erosion, and fluoride is the main agent used to enhance enamel remineralization. ${ }^{5,6}$ However, to control mineral loss caused by erosion, high concentrations and frequency seem to be needed, because the protective effect of fluoride against demineralization depends on the $\mathrm{pH}$ level, $\mathrm{F}$ 
concentration, type of $\mathrm{F}$ salt and presence of mineral ions $(\mathrm{Ca}$ and $\mathrm{P})$ in the saliva and in the agents. ${ }^{5-7}$ Sodium fluoride varnishes have been used due to their ability to adhere to the tooth surface and their high fluoride concentration, which increases the formation of calcium fluoride $\left(\mathrm{CaF}_{2}\right)$ deposits that act as fluoride reservoirs. ${ }^{4-6}$

In recent years, other agents for inhibiting erosion have been investigated, such as casein phosphopeptides with amorphous calcium phosphate complex (CPP-ACP). ${ }^{8-10}$ CPP-ACP complex may increase the level of calcium and inorganic phosphate ions at the tooth surface, thereby permitting immediate enamel surface remineralization. ${ }^{8-10}$ Additionally, there have been advancements in nanotechnological developments of products for the remineralization of enamel, such as nano-hydroxyapatite (HA). ${ }^{11}$ However, HA has been studied only as a biomimetic material to remineralize enamel carious lesions, ${ }^{11}$ whereas its effect on eroded enamel has not been investigated.

Calcium nanophosphate organized in the crystalline form of HA was recently developed as a paste. Calcium nanophosphate crystals are smaller than $100 \mathrm{~nm}$, leading to improved bioactivity of the product, resulting from the increase in surface area and wettability of HA nanoparticles (manufacturer's information). Calcium, phosphate and fluoride ions are released and organized in fluorapatite and $\mathrm{CaF}_{2}$ on demineralized tooth surfaces. Based on these mechanisms, it would be interesting to evaluate the effect of this bioactive material on erosion prevention, in comparison with other remineralizing agents.

The aim of this study was to investigate the in $v i$ tro effect of fluoride varnish, calcium nanophosphate HA paste and CPP-ACP paste on preventing the development of enamel erosion. The null hypothesis tested was that there would be no difference between the effects of fluoride varnish and of remineralizing pastes on enamel microhardness and surface topography after an in vitro erosive challenge.

\section{Methodology}

\section{Specimen preparation}

After obtaining approval from the Universidade Federal de Campina Grande - UFCG Research Ethics Committee (11/2011), forty sound human third molars were selected for this study. The teeth were stored in $0.1 \%$ thymol at $4^{\circ} \mathrm{C}$ and used within 1 month after extraction. Two enamel specimens $(4 \times 4 \times 2 \mathrm{~mm})$ were obtained from the buccal and lingual surfaces of each tooth, using a water-cooled low-speed diamond saw (Isomet; Buehler Ltd., Lake Bluff, USA). Next, they were embedded in acrylic resin (Vipi Flash, Pirassununga, Brazil), and the enamel surfaces were ground flat with $\mathrm{SiC}$ paper discs (400, 600 and 1200 grades) and polished with $1 \mu \mathrm{m}$ alumina suspension (Erios Corp., São Paulo, Brazil). Afterwards, the baseline hardness of the enamel surface was determined and specimens with a KHN between 300 and 380 were selected ${ }^{12,13}$ and randomly divided into 4 groups $(\mathrm{n}=12)$, according to the agent applied:

- control, no treatment;

- fluoride varnish (Duraphat, Colgate, São Paulo, Brazil);

- calcium nanophosphate paste (Desensibilize Nano P, FGM Produtos Odontológicos, Joinville, Brazil) and

- CPP-ACP paste (MI Paste Plus, GC America Inc., Alsip, USA; Table 1).

\section{Treatment}

Before exposure to acid, $0.3 \mathrm{~mL}$ of each agent was inserted into an insulin syringe (BD Ultra-fine, Franklin Lakes, USA) to standardize the volume of product applied to the enamel surface. The volume of $20 \mu \mathrm{L}$ of all agents was sufficient to cover the surface of the specimens. Thus, according to each group, $20 \mu \mathrm{L}$ of the agent was applied to the

Table 1 - Composition of remineralizing agents.

\begin{tabular}{l|l}
\hline \multicolumn{1}{c|}{ Agent } & \multicolumn{1}{c}{ Composition (batch number) } \\
\hline $\begin{array}{l}\text { MI Paste Plus } \\
\text { (GC America } \\
\text { Inc.) }\end{array}$ & $\begin{array}{l}\text { Water, glycerol, CPP-ACP, D-sorbitol, CMC } \\
\text { propylene glycol, silicone and titanium } \\
\text { dioxide, xylitol, phosphoric acid, flavor, sodium } \\
\text { saccharin, ethyl propyl butyl p-hydroxybenzoate, } \\
900 \text { ppm sodium fluoride (090813M) }\end{array}$ \\
\hline $\begin{array}{l}\text { Desensibilize } \\
\text { Nano P (FGM) }\end{array}$ & $\begin{array}{l}\text { Calcium nanophosphate organized in crystalline } \\
\text { form of hydroxyapatite, potassium nitrate, } \\
\text { water, surfactant, tensoactive, flavor, 9000 ppm } \\
\text { sodium fluoride (170610) }\end{array}$ \\
\hline $\begin{array}{l}\text { Duraphat } \\
\text { (Colgate) }\end{array}$ & $\begin{array}{l}\text { Alcohol, natural resins, wax, saccharine, flavor, } \\
22600 \text { ppm sodium fluoride (P008203LA) }\end{array}$ \\
\hline
\end{tabular}


specimens, in accordance with the manufacturer's instructions:

1. Varnish was applied and specimens were stored in artificial saliva. After $24 \mathrm{~h}$, cotton tips were immersed in deionized water and applied to the surface to soften the varnish. The varnish was removed with a scalpel blade, ${ }^{12}$ taking care to avoid touching the surface;

2. Desensibilize Nano P paste was rubbed on with a microbrush for $10 \mathrm{~s}$. After this, the paste was kept in contact with the enamel for 5 minutes and removed with deionized water;

3. MI Paste Plus was applied and kept in contact with the enamel for 5 minutes and then removed with deionized water. Paste application time was standardized at 5 minutes.

\section{Erosive challenge and treatment}

Specimens were immersed in a cola drink (CocaCola ${ }^{\circledR}$, Jundiaí, Brazil; pH 2.3), using separate containers (10 mL/specimen), at room temperature, for 5 minutes 4 times/day. ${ }^{14}$ The specimens were rinsed thoroughly with deionized water and immersed in artificial saliva, pH 7.0 (10 mL/block) at room temperature for $2 \mathrm{~h}$, between erosive challenges ${ }^{14}$ and overnight. The artificial saliva was made according to the Moretto et al. ${ }^{14}$ study. This erosive challenge was repeated for 5 days. The cola drink and artificial saliva were changed after every cycle. During the demineralization cycles, the specimens were kept in hermetically sealed containers to prevent the loss of gas, which can increase the $\mathrm{pH} \cdot{ }^{15}$ The enamel specimens were exposed to one of the pastes immediately after each erosive challenge. ${ }^{14}$ The fluoride varnish was applied only once, just before the erosive challenge, to simulate a clinical situation. ${ }^{12,16,17}$

\section{Hardness assessment}

Microhardness is the most useful method of assessing enamel softening caused by erosion. ${ }^{18}$ Enamel hardness (KHN) was measured with a Knoop microhardness diamond applied under a $25 \mathrm{~g}$ load for 10 s (HMV II; Shimadzu Corporation, Kyoto, Japan) at baseline and after 5 days of erosive challenge. All readouts were performed by the same examiner. Five indentations were made in each readout, at least $50 \mu \mathrm{m}$ apart, and their average represented the specimen KHN value. In addition, the percentage of hardness loss (\% KHN change) was calculated using the following formula:

$$
\%=100\left(\mathrm{KHN}_{(I)}-\mathrm{KHN}_{(\mathrm{F})}\right) / \mathrm{KHN}_{(I)},
$$

where $\mathrm{KHN}_{(\mathrm{I})}$ is the average of the initial hardness measurements and $\mathrm{KHN}_{(\mathrm{F})}$ is the average of the final hardness values. ${ }^{12}$

\section{Atomic force microscopy}

AFM is an important tool for obtaining a source of new structural information. ${ }^{19}$ Three randomized specimens of each group were analyzed using atomic force microscopy (AFM; SPM-9600, Shimadzu Corp., Kyoto, Japan). Each specimen was fixed to the microscope holder on a stub $(2 \times 3 \mathrm{~mm})$. The block surface morphology was probed in "contact mode." Imaging was performed with a standard geometry silicon nitride Micro-Cantilever (OMCL-TR, Olympus, Tokyo, Japan) and probed with $0.15 \mathrm{~N} / \mathrm{m}$ constant elastic and $24 \mathrm{kHz}$ resonant frequency. Images $30 \mu \mathrm{m} \times 30 \mu \mathrm{m}$ with resolution of $512 \times 512$ pixels and an operating point of $1.5 \mathrm{~V}$ were collected at a very low scan rate to obtain details of the enamel structure and to avoid damaging the tip.

\section{Statistical analysis}

Data analysis was performed with the GraphPad Instat version 2.0 (GraphPad software, La Jolla, USA) at a level of significance of $\alpha=0.05$. Since all the variables tested satisfied the assumptions of equality and normal distribution, one-way ANOVA and Tukey's test were carried out for statistical comparisons of enamel hardness change percentages. The paired t-test was used to compare the enamel hardness before and after the erosive challenge in the same group.

\section{Results}

Table 2 shows the following KHN values for all groups:

- initial,

- after erosion, and

- \%KHN change. 
Table 2 - Change in surface hardness $(\mathrm{KHN})$ of enamel after erosion by a cola beverage, expressed in mean \pm standard deviation.

\begin{tabular}{c|c|c|c}
\hline Agent/treatment & Initial KHN & KHN after erosion & \%KNH change \\
\hline Control & $351.3 \pm 10.7^{a *, A * *}$ & $96.8 \pm 11.4^{a, B}$ & $72.4 \pm 3.0^{a *}$ \\
\hline Fluoride varnish & $354.4 \pm 24.6^{a, A}$ & $91.7 \pm 14.1^{a, B}$ & $73.4 \pm 5.5^{a}$ \\
\hline Nanophosphate & $367.1 \pm 6.5^{a, A}$ & $187.2 \pm 27.9^{\mathrm{b}, \mathrm{B}}$ & $49.0 \pm 7.9^{\mathrm{b}}$ \\
\hline CPP-ACP & $360.4 \pm 10.1^{\mathrm{a}, \mathrm{A}}$ & $141.8 \pm 16.5^{\mathrm{c}, \mathrm{B}}$ & $60.6 \pm 4.0^{\mathrm{c}}$ \\
\hline
\end{tabular}

* Same lowercase letters indicate that there was no significant difference among the agents in each treatment and in the \% KNH change among agents (one-way ANOVA and Tukey's test, $p>0.05$ ). ${ }^{* *}$ Same uppercase letters indicate that there was no significant difference between initial and post-erosion values of each agent (paired-T test, $p>0.05$ ).

No statistically significant differences were observed among the groups for initial $\mathrm{KHN}$ values $(p=0.87)$. After erosion, all groups showed lower $\mathrm{KHN}$ values $(p<0.05)$, in comparison with the initial values.

After the erosive challenge, there was no statistically significant difference between the control and varnish groups $(p=0.79)$, which showed the highest KHN loss values. Furthermore, the control and varnish groups showed a statistically significant difference in the remineralizing pastes used $(p<0.05)$. The nanophosphate group showed a lower KHN loss value, compared with the CPP-ACP group, after the erosive challenge $(p<0.05)$. There was a significant amount of protection against demineralization produced by nanophosphate paste, represented by the highest KHN value after erosion, compared with the CPP-ACP, the varnish and the control groups $(p<0.001)$. The varnish and control groups showed no statistically significant difference with regard to $\% \mathrm{KHN}$ change $(p=0.75)$.

Figures 1, 2, 3 and 4 show the AFM images after applying the remineralizing agent and erosive challenge. The control and varnish groups showed similar topography. Figures 1 and 2 showed areas of demineralized enamel with a honeycomb-like structure and a rough surface without a protective layer (Figure $1 \mathrm{~B}$ and $2 \mathrm{~B}$ ). The treatment with the two pastes caused different surface topographies. The CPP-ACP group showed a surface interspersed with globular deposits (Figure 3). The nanophosphate group showed progressive microparticle deposition, and the interprismatic and prismatic enamel structures appeared to be completely hidden by a thick homogeneous layer (Figures 4).

\section{Discussion}

The present study is an innovative investigation about the potential for remineralization of eroded enamel with a new agent containing calcium nanophosphate organized in HA crystals. The microhardness test and AFM were used. The standardization of baseline enamel KHN (Table 2) made it possible to establish the $\% \mathrm{KHN}$ change among the groups after treatment.

Formation of the $\mathrm{CaF}_{2}$-like layer by fluoride (F) agents on eroded dental surfaces partially reduces enamel mineral loss by subsequent erosion. ${ }^{14}$ High-concentrated $\mathrm{F}$ applications have been considered very effective in reducing the enamel erosion. ${ }^{6,20}$ The agents investigated contain approximately 22600 ppm F (varnish), 9000 ppm F (nanophosphate paste) and $900 \mathrm{ppm}$ F (CPP-ACP paste), according to the manufacturers' information. Although the varnish contained the highest $\mathrm{F}$ concentration among the agents tested, according to our protocol, it showed no protective effect against enamel erosion. This could be observed by the statistically lower remineralization rates (represented by a loss in $\mathrm{KHN}=$ higher $\% \mathrm{KHN}$ change), as compared with the CPP-ACP and nanophosphate groups (Table 2). Furthermore, no statistically significant difference was found for KHN values and surface topography (Figures 1 and 2) between the varnish and control groups (Table 2). Figures $1 \mathrm{~A}$ and $2 \mathrm{~A}$ showed that the enamel demineralization caused by the cola beverage involved mainly the inner area of the prism, and created a honeycomb-like structure, as described by Poggio et al. ${ }^{10}$

The varnish was removed after $24 \mathrm{~h}$ to simulate in vivo conditions (a single professional application 
Figure 1 - AFM image of enamel surface after erosive challenge and application of no agent; $(\mathbf{A})(\rightarrow)$ honeycomb-like structure of enamel; (B) rough surface with no protection layer.
A

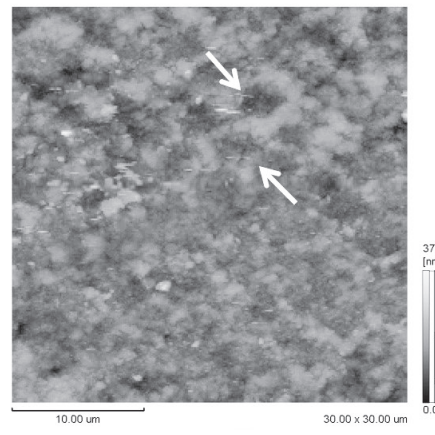

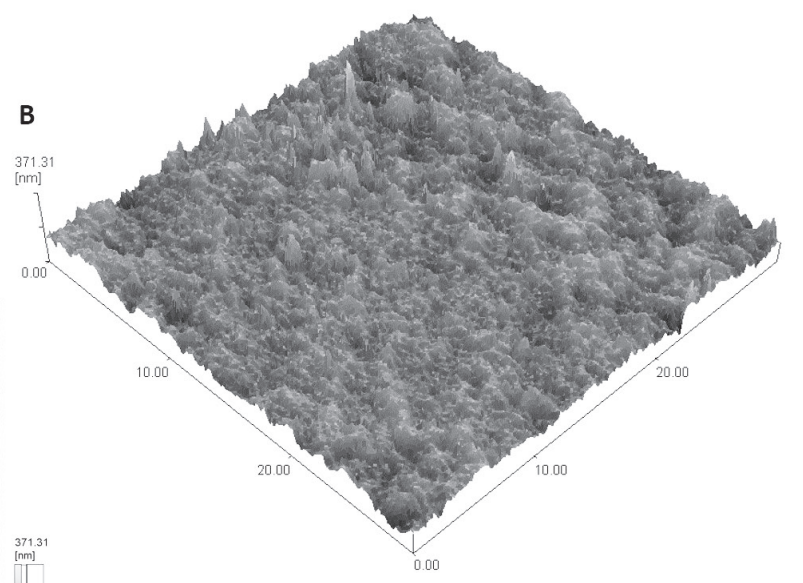

$30.00 \times 30.00[\mathrm{um}] \quad z 0.00-371.31[\mathrm{~nm}]$

Figure 2 - AFM image of enamel surface after erosive challenge and varnish application; $(\mathbf{A})(\rightarrow)$ honeycomb-like structure of enamel; (B) rough surface with no protection layer.

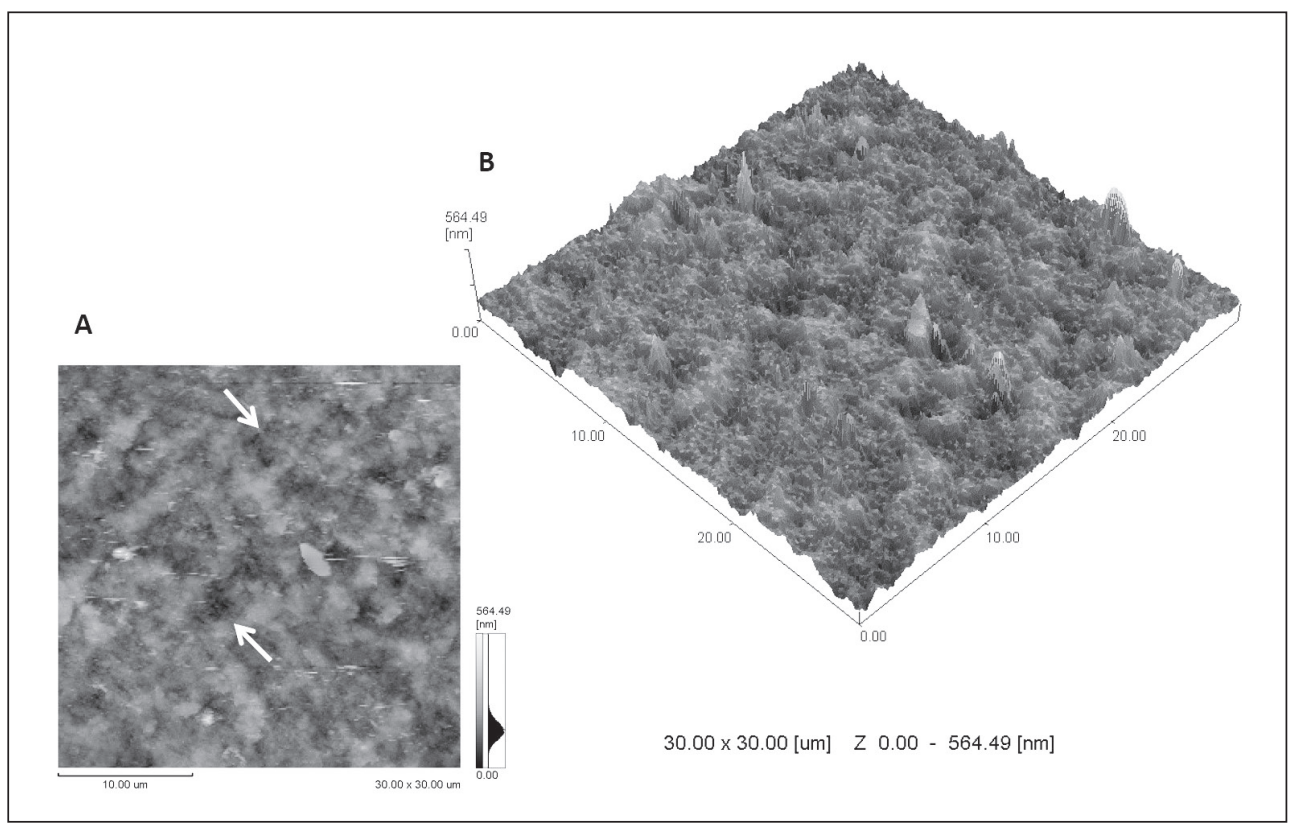

was made every 7 days), as used in other in vitro studies. ${ }^{12,16,17}$ The fluoride varnish may have reacted chemically with the enamel during the first $24 \mathrm{~h}$, but this reaction was not enough to reduce the enamel loss caused by the erosive attack. Figure $2 \mathrm{~B}$ shows a rough and eroded surface with no formation of a protective layer for the varnish group, visualized as a honeycomb-like demineralized enamel structure (Figure 2A). In some studies, which showed the pro- tective effect of fluoride varnish against dental erosion, ${ }^{21}$ the varnishes were not completely removed during the experimental period, and this mechanical protection may have played a role in the protective effect evidenced.

Apart from fluoride, the CPP-ACP complex showed an increase in enamel microhardness and a decrease in enamel surface roughness after erosion by cola drinks. ${ }^{9,10,13}$ However, the mechanism 
Figure 3 - AFM image of enamel surface after erosive challenge and CPP-ACP paste application; $(\mathbf{A}, \mathbf{B})$ surface with globular nonhomogeneous deposits; $(\rightarrow)$ adherent irregularities.

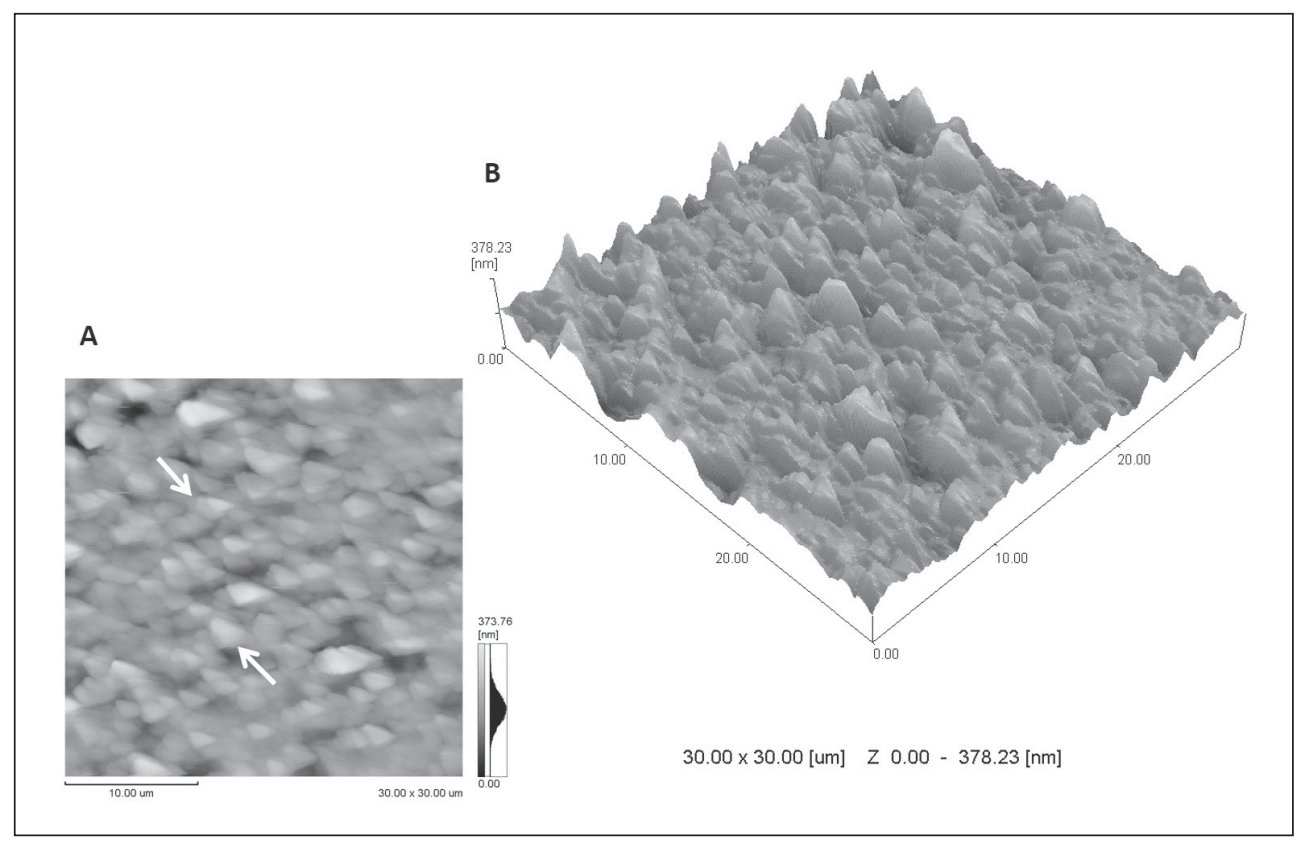

Figure 4 - AFM image of enamel surface after erosive challenge and nanophosphate paste application; (A) homogeneous deposit on the surface; (B) enamel completely hidden by a thick homogeneous layer.

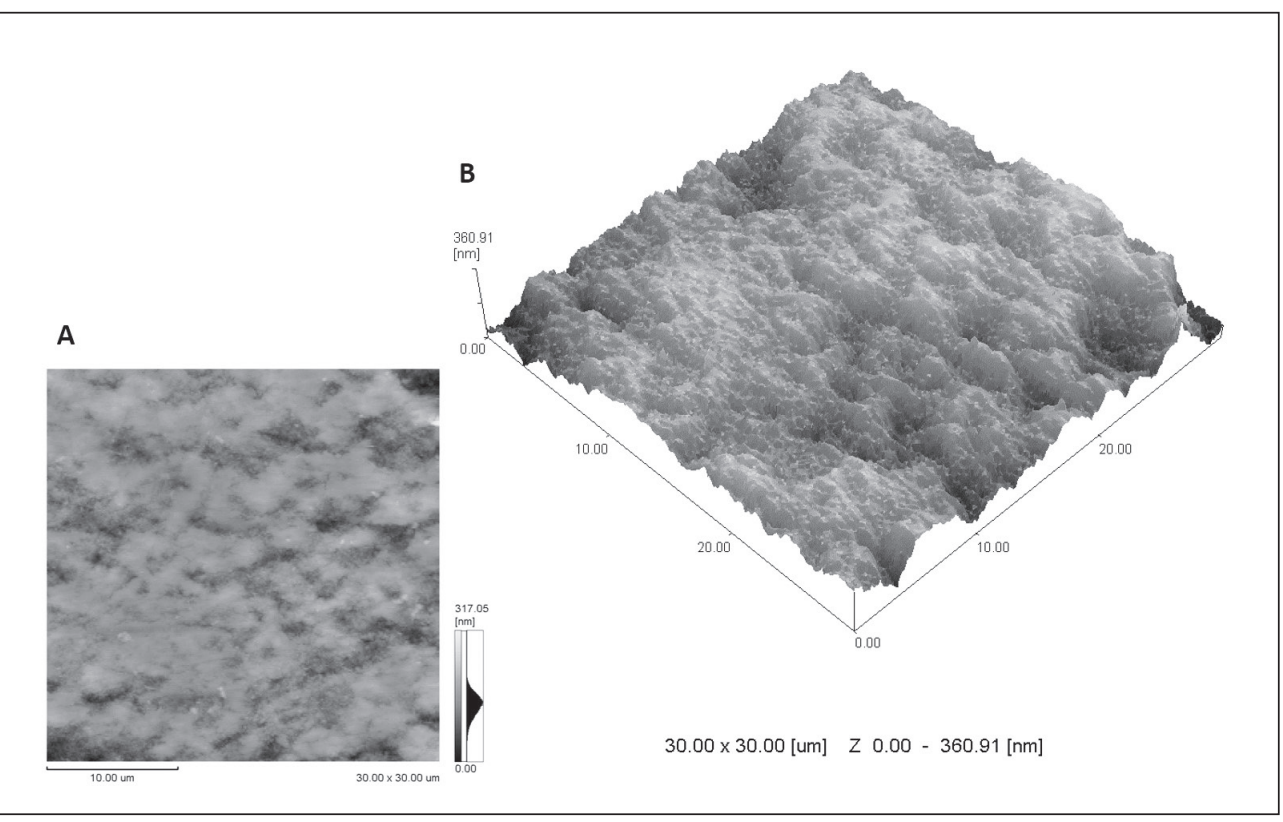

by which the process of remineralization of eroded lesions by CPP-ACP occurs is unclear. It is known that CPP-ACP increases the number of potential calcium-binding sites, thereby decreasing the constant diffusion of calcium. ${ }^{9}$ Furthermore, ACP at the tooth surface buffers the free calcium and phosphate ion activities, thus helping to maintain a state of supersaturation that depresses demineralization and enhances remineralization. ${ }^{9}$

The CPP-ACP group showed a higher KHN value and lower mineral loss (\%KHN), compared with the control group, after the erosive challenge (Table 2). However, the nanophosphate group showed the highest KHN value after erosion, with significantly lower mineral loss than the CPP-ACP paste (Table 2 ). Because there was no investigation into nano- 
phosphate paste on eroded enamel surface, it was difficult to compare the results found in the present study with others in the literature. However, it can be implied that the application method of this paste (10 s of friction) influenced the results. The calcium nanophosphate crystals may have penetrated more deeply into the defects of the eroded enamel, forming a "reservoir-like" deposit of calcium and phosphate ions. The reservoir-like deposit could make these ions available during a subsequent erosive challenge and help maintain a state of supersaturation with enamel minerals. ${ }^{11}$ Furthermore, the F concentration in the nanophosphate paste is 10 times higher (9000 ppm) than that of the CPP-ACP paste (900 ppm). This higher concentration may affect the remineralization process. It was confirmed in an earlier investigation that there is a synergistic effect of $\mathrm{F}$ ions with CPP$\mathrm{ACP}$ in the remineralization of eroded enamel. ${ }^{22}$ The remineralization potential of CPP-ACP paste can also be improved through the application of fluoridated toothpaste, which would increase the F concentration against an erosive attack. ${ }^{13}$

Although AFM analyses showed that a protective layer had formed on the enamel surface following CPP-ACP application, non-homogeneous deposits with adherent irregularities, appearing as globular structures, were observed (Figures 3). These apparent structures were also cited by Poggio et al. ${ }^{10,19}$ According to these authors, ${ }^{10,19}$ it is likely that CPP-ACP paste causes the formation of a layer that fills the interprismatic cavities and partially covers the prisms. Otherwise, the nanophosphate

\section{References}

1. Lussi A, Schlueter N, Rakhmatullina E, Ganss C. Dental Erosion - an overview with emphasis on chemical and histopathological aspects. Caries Res. 2011 May;45 Suppl 1:2-12.

2. Lussi A, Jaeggi T, Zero D. The role of diet in the aetiology of dental erosion. Caries Res. 2004;38 Suppl 1:34-44.

3. Scaramucci T, Hara AT, Zero DT, Ferreira SS, Aoki IV, Sobral MA. Development of an orange juice surrogate for the study of dental erosion. Braz Dent J. 2011;22(6):473-78.

4. Gonçalves GK, Guglielmi CA, Corrêa FN, Raggio DP, Corrêa MS. Erosive potential of different types of grape juices. Braz Oral Res. 2012 Sep-Oct;26(5):457-63. group showed progressive microparticle deposition with interprismatic and prismatic enamel structures completely hidden by a thick homogeneous layer, probably due to HA nanocrystals (Figures 4).

It can be assumed that none of the agents investigated provided protection against the development of erosion; however, the calcium nanophosphate paste reduced enamel surface softening. This paste may provide a potential treatment option for patients suffering from enamel erosion. Further studies are needed to investigate whether the protective effect of calcium nanophosphate paste is stable against abrasion and in vivo erosion. The null hypothesis was rejected because there were significant differences in KHN values and AFM topography among the varnish and remineralizing pastes.

\section{Conclusion}

Although none of the products investigated provided protection against the development of erosion, calcium nanophosphate paste reduced the erosion, as compared with other agents.

\section{Acknowledgments}

The authors are grateful to FGM Produtos Odontológicos and GC America Inc. for providing the products, and to Prof. Severino J. Guedes de Lima of Laboratório de Solidificação Rápida / Universidade Federal da Paraíba (LSR/UFPB) for AFM use. This investigation was supported by Conselho Nacional de Desenvolvimento Científico e Tecnológico - CNPq (47550/2010-2).

5. Serra MC, Messias DC, Turssi CP. Control of erosive tooth wear: possibilities and rationale. Braz Oral Res. 2009;23 Suppl 1:49-55.

6. Magalhães AC, Wiegand A, Rios D, Honório HM, Buzalaf MA. Insights into preventive measures for dental erosion. J Appl Oral Sci. 2009 Mar-Apr;17(2):75-86.

7. Saxegaard E, Rølla G. Fluoride acquisition on and in human enamel during topical application in vitro. Scand J Dent Res. 1988 Dec;96(6):523-35.

8. White AJ, Gracia LH, Barbour ME. Inhibition of dental erosion by casein and casein-derived proteins. Caries Res. 2011 Dec;45(1):13-20. 
9. Ranjitkar S, Kaidonis JA, Richards LC, Townsend GC. The effect of CPP-ACP on enamel wear under severe erosive conditions. Arch Oral Biol. 2009 Jun;54(6):527-32.

10. Poggio C, Lombardini M, Dagna A, Chiesa M, Bianchi S. Protective effect on enamel demineralization of a CPP-ACP paste: an AFM in vitro study. J Dent. 2009 Dec;37(12):949-54.

11. Huang S, Gao S, Cheng L, Yu H. Remineralization potential of nano-hydroxyapatite on initial enamel lesions: an in vitro study. Caries Res. 2011 Sep;45(5):460-68.

12. Murakami C, Bönecker M, Corrêa MS, Mendes FM, Rodrigues CR. Effect of fluoride varnish and gel on dental erosion in primary and permanent teeth. Arch Oral Biol. 2009 Nov;54(11):997-1001.

13. Tantbirojn D, Huang A, Ericson MD, Poolthong S. Change in surface hardness of enamel by a cola drink and a CPP-ACP paste. J Dent. 2008 Jan;36(1):74-9.

14. Moretto MJ, Magalhães AC, Sassaki KT, Delbem AC, Martinhon CC. Effect of different fluoride concentrations of experimental dentifrices on enamel erosion and abrasion. Caries Res. 2010 Apr;44(2):135-40.

15. Parry J, Shaw L, Arnaud M, Smith A. Investigation of mineral waters and soft drinks in relation to dental erosion. J Oral Rehabil. 2001 Aug;28(8):766-72.

16. Magalhães AC, Kato MT, Rios D, Wiegand A, Attin T, Buzalaf MA. The effect of an experimental $4 \% \mathrm{TIF}_{4}$ varnish compared to NAF varnishes and $4 \% \mathrm{TIF}_{4}$ solution on dental erosion in vitro. Caries Res 2008 Jun;42(4):269-74.

17. Magalhães AC, Stancari FH, Rios D, Buzalaf MA. Effect of an experimental $4 \%$ titanium tetrafluoride varnish on dental erosion by a soft drink. J Dent. 2007 Nov;35(11):858-61.

18. Shellis RP, Ganss C, Ren Y, Zero DT, Lussi A. Methodology and models in erosion research: discussion and conclusions. Caries Res. 2011;45 Suppl 1:69-77.

19. Poggio C, Lombardini M, Colombo M, Bianchi S. Impact of two toothpastes on repairing enamel erosion produced by a soft drink: an AFM in vitro study. J Dent. 2010 Nov;38(11):868-74.

20. Magalhães AC, Rios D, Honório HM, Delbem AC, Buzalaf MA. Effect of $4 \%$ titanium tetrafluoride solution on the erosion of permanent and deciduous human enamel: an in situ/ ex vivo study. J Appl Oral Sci. 2009 Jan-Feb;17(1):56-60.

21. Sorvari R, Meurman JH, Alakuijala P, Frank RM. Effect of fluoride varnish and solution on enamel erosion in vitro. Caries Res.1994;28(4):227-32.

22. Srinivasan N, Kavitha M, Loganathan SC. Comparison of the remineralization potential of CPP-ACP and CPP-ACP with 900 ppm fluoride on eroded human enamel: an in situ study. Arch Oral Biol. 2010 Jul;55(7):541-44. 